\title{
Ranking Fuzzy Numbers with Fuzzy Analytical Hierarchy in Risk Assessment
}

\author{
Fatin Amirah Ahmad Shukri' ${ }^{1,2, *}$, Zaidi Isa ${ }^{2}$ \\ ${ }^{1}$ Centre for Foundation Studies, National Defence University of Malaysia, Malaysia \\ ${ }^{2}$ School of Mathematical Sciences, Faculty of Science and Technology, National University of Malaysia, Malaysia
}

Received June 16, 2020 ; Revised July 3, 2020; Accepted July 20, 2020

Copyright $\bigcirc 2020$ by authors, all rights reserved. Authors agree that this article remains permanently open access under the terms of the Creative Commons Attribution License 4.0 International License

\begin{abstract}
Risk in the construction industry is an important factor which must be considered in every decision. To ensure the smooth operation of any project, construction risk factors need to be investigated and assessed. For this reason, the evaluation of the risk factor is determined using expert opinion. Four main risk categories are used in this study, namely risk on project management, engineering risk, implementation risk, and supplier risk. The purpose of this study is to implement a fuzzy analytical hierarchy process (fuzzy AHP), a method that has been receiving increased interest in decision making situations to determine the relative importance of the criteria used for the decision when calibrating the end of each risk factor stage. A paired comparison was employed for subjective judgment made by experts in order to compute the priority weight vector for each risk item. Results show that the risk on supplier carries the highest weight (0.91), followed by the risk of accidents on site (0.58) and less motivation among the project management team (0.55). The final relative weight at the last level of the hierarchy gives a signal to the decision maker of organization of all the possible impacts of the risks revealed. Hence, the application of fuzzy AHP in ranking risk factors has demonstrated better results and more flexibility in human decision making.
\end{abstract}

Keywords Fuzzy Set Theory, Fuzzy Ranking, Risk, Construction Risk, Fuzzy AHP

\section{Introduction}

Risk factor assessment in the construction sector is a multi-criteria decision-making (MCDM) challenge with many quantitative and qualitative characteristics (Mousa, 2015; Taroun, 2014; Taylan, Bafail, Abdulaal \& Kabli, 2014). Since human decision-making typically entails fuzziness and vagueness (Chen, 2011), a fuzzy analytical hierarchy process (AHP) approach is used to solve the problem. In order to deal with this complexity, fuzzy logic provides a comprehensive approach (Shang \& Hossen, 2013) and is commonly accepted by scholars from diverse fields and contexts around the world. Pioneer work on the fuzzy set theory was started in the pre-1960s by incorporating the uncertainty of human thoughts in modelling (Zadeh, 1965). The fuzzy sets theory has advanced in a variety of ways and in many disciplines. Throughout the 1970s and 1980s, developments of fuzzy logic and a great volume of fuzzy system theories with important practical applications have emerged as one of the robust methods used by researchers and practitioners.

Over the last few decades, numerous ranking approaches have been proposed. Hang (2011) has established a logistics park location evaluation indicator system based on AHP by considering both qualitative and quantitative factors. Chen (2011) suggested a fuzzy AHP approach to assess customer value in an electronic trading company called Business To Consumer (B2C). The key voice criterias for customers in telecommunications manufacturing companies by the AHP method were subsequently listed by Rahnama, Kheibari, Hossein Pour, and Najafi in 2012. Reddy (2015) highlighted the advantages of using trapezoidal fuzzy numbers over a triangular in Chang's extent analysis method on fuzzy AHP. Other studies by Hajjari and Numbers (2014) carried out a thorough review on the mathematical ranking method by various researchers (Baas \& Kwakernaak, 1977; Liu \& Han, 2005; Wang \& Lee, 2007) and proposed new methods to overcome the mentioned weaknesses. In the area of natural sciences, Radionovs and Užga-Rebrovs (2016) analyse the ecological risk assessment towards human health using the fuzzy based technique.

Recent publication can be seen in the area of operation research. Al-Shammari and Mili (2019) have demonstrated an extensive numerical example for sensitivity analysis 
which resulted in the strength and plausibility of the FAHP approach. Wan Mohd and Abdullah (2017) ranked the importance of each experts' opinions using intuitionistic fuzzy Choquet integral and shown a reliable method for MCDM problems. Based on the above literature, this study provides a risk assessment model based on fuzzy set theory, along with an illustrative example of the proposed methodology in project construction. The aim of this paper is to determine the relative importance of the decision-making criteria using fuzzy AHP and consequently, to determine the overall ranking of the risk factor of project based on Malaysia.

This paper uses four main risk factors in the construction industry as proposed by Nieto-Morote and Ruz-Vila (2011) and its underlying triangular fuzzy scales. The paper is organised in the following ways: section 2 provides a summary of fuzzy AHP, while section 3 illustrates the numerical example of using the fuzzy AHP. Finally, section 4 suggests a way forward for future research especially, in a complex and uncertain environment.

\section{Steps in Fuzzy AHP}

Analytic Hierarchy Process (AHP) as proposed by Saaty (1980), is a traditional yet powerful decision-making methodology used to determine the priorities amongst different criteria, compare alternatives for each criterion, and determine an overall ranking of the alternatives. The final result of the AHP provides the best choice of decision-making alternatives. The basic procedure for the implementation of AHP consists of the following steps:

- Decomposing the decision problem into a hierarchy. The overall objective of the decision problem is represented by the top hierarchy, the intermediate level represents the criteria and sub-criteria which affect the decision and low level constitutes the potential alternatives

- Calculation by pair-wise analysis of the relative weights of the decision criteria at each point of the hierarchy. In this stage, the decision-making body uses the basic scale or weight of 1 (equal importance) and 9 (extreme importance), as specified by Saaty (1980) to evaluate the priority score of the same level for each couple of criteria.

- That is, the pair-wise comparison matrix is constructed in which the elements $a_{i j}$ inside the matrix can be interpreted as the degree of precedence of the $i$ th criterion over the $j$ th criterion. Then, the average weight for each normalised criterion is computed (Chen, 2011). In this paper, researchers used the 5-point scale described by Nieto-Morote and Ruz-Vila (2011).

- Evaluating the decision alternatives taking into account the weights of decision criteria. The alternative scores are combined with the criterion weights to produce an overall score for each alternative. The AHP provides the consistency rate (CR) of the decision-maker to calculate the uniformity of judgement provided in the fuzzy AHP section.

As reported by Lee and $\mathrm{Ph}$ (2016), the conventional AHP is inadequate in dealing with the imprecise or vague nature of linguistic assessment, whilst in fuzzy AHP, common-sense linguistic statements have been used in the pair-wise comparison which can be expressed by the triangular fuzzy numbers (TFNs). As a result, the pair-wise comparisons and the integration of priorities are aggregated to determine the overall goals of the decision-making mechanism (Radionovs \& Užga-Rebrovs, 2016).

\subsection{Fuzzy AHP}

Fuzzy AHP is one of the fuzzy ranking methods using pair-wise comparison criteria. In general, TFNs used in a pair-wise comparison are described by three real numbers represented as a triple $(l, m, u)$ where $l \leq m \leq u$ is used to denote a fuzzy event (Chang, 1996) as shown in Table 1. Fuzzy AHP differs from conventional in terms of it accommodates uncertainty in human judgment. In many practical situations, human estimate or preference is always subjective and qualitative, hence it is desirable to use fuzzy evaluation.

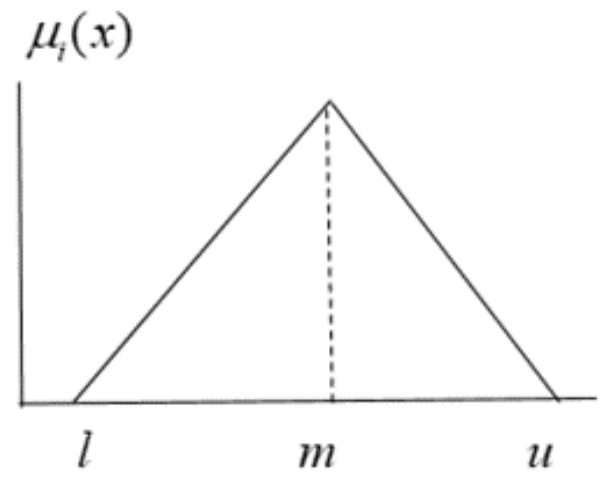

Figure 1. Triangular fuzzy numbers

The fuzzy AHP process are as follows:

$$
\mathrm{S}_{\mathrm{i}}=\sum_{\mathrm{j}=1}^{\mathrm{m}} M_{g i}^{j} \times\left[\sum_{\mathrm{i}=1}^{\mathrm{n}} \sum_{\mathrm{j}=1}^{\mathrm{m}} M_{g i}^{j}\right]^{-1}
$$

Where:

$$
\sum_{j=1}^{m} M_{g i}^{j}=\left(\sum_{j=1}^{m} l_{j}, \sum_{j=1}^{m} m_{j},\right.
$$

and

$$
\left[\sum_{\mathrm{i}=1}^{\mathrm{n}} \sum_{\mathrm{j}=1}^{\mathrm{m}} M_{g i}^{j}\right]^{-1}=\left(\frac{1}{\sum_{j=1}^{m} u_{j}}, \frac{1}{\sum_{j=1}^{m} m_{j}}, \frac{1}{\sum_{j=1}^{m} l_{j}}\right)
$$

Applying Chang's extent analysis (1996) to measure the 
degree of possibility $S_{b} \geq S_{a}$

$$
\begin{gathered}
\mathrm{V}\left(\mathrm{S}_{\mathrm{b}} \geq \mathrm{S}_{\mathrm{a}}=1, \text { if } m_{b} \geq m_{a}\right. \\
0, \text { if } l_{a} \geq u_{b} \\
\frac{l_{a}-u_{b}}{\left(m_{b}-u_{b}\right)-\left(m_{a}-l_{a}\right)} \quad, \text { otherwise } \\
\mathrm{V}\left(\mathrm{S}_{\mathrm{b}} \geq \mathrm{S}_{\mathrm{a}}\right)=\operatorname{hight}\left(\mathrm{S}_{\mathrm{b}} \cap \mathrm{S}_{\mathrm{a}}\right)=\mu_{\mathrm{S}_{\mathrm{a}}}(\mathrm{d})
\end{gathered}
$$

Therefore, the relative criteria weight is given by:

$$
\mathrm{V}\left(\mathrm{S}_{\mathrm{i}} \geq \mathrm{S}_{1}, \mathrm{~S}_{2}, \ldots ., \mathrm{S}_{\mathrm{k}}\right)=\mathrm{V}\left(\mathrm{S}_{\mathrm{i}} \geq \mathrm{S}_{\mathrm{k}}\right)=\mathrm{w}^{\prime}\left(\mathrm{S}_{\mathrm{i}}\right)
$$

\section{Numerical Example}

In this section, we present a numerical example to make our approach more understandable. Data were collected from one of the commercial building projects in Kuala Lumpur, Malaysia. The construction of a 16-storey service apartment is taken as an example to demonstrate the suitability of the proposed risk assessment methodology. Four experts from this project, namely the architect, quantity surveyor, engineer, and project manager, with more than 10 years of experience and qualifications in building projects, were selected to answer a questionnaire based on the analysis of risk factors by Nieto-Morote and Ruz-Vila (2011).

\subsection{Pair-wise Comparison}

Pair-wise comparisons are fundamental building blocks of the fuzzy AHP. In the fuzzy AHP, it is assumed that each element is displayed as a risk factor for lower-level hierarchical structure (Ling \& Xu, 2012) and expressed as fuzzy numbers. It is a combination of the fuzzy evaluation of the probability of an adverse event and the fuzzy evaluation of potential losses related to the implementation of this event (Lee \& Ph, 2016). This paper has identified risk factors for a commercial building based upon the existing literature, since it featured similarly as in the construction risk assessment. The following three levels of hierarchy model were then constructed. (Fig.2)

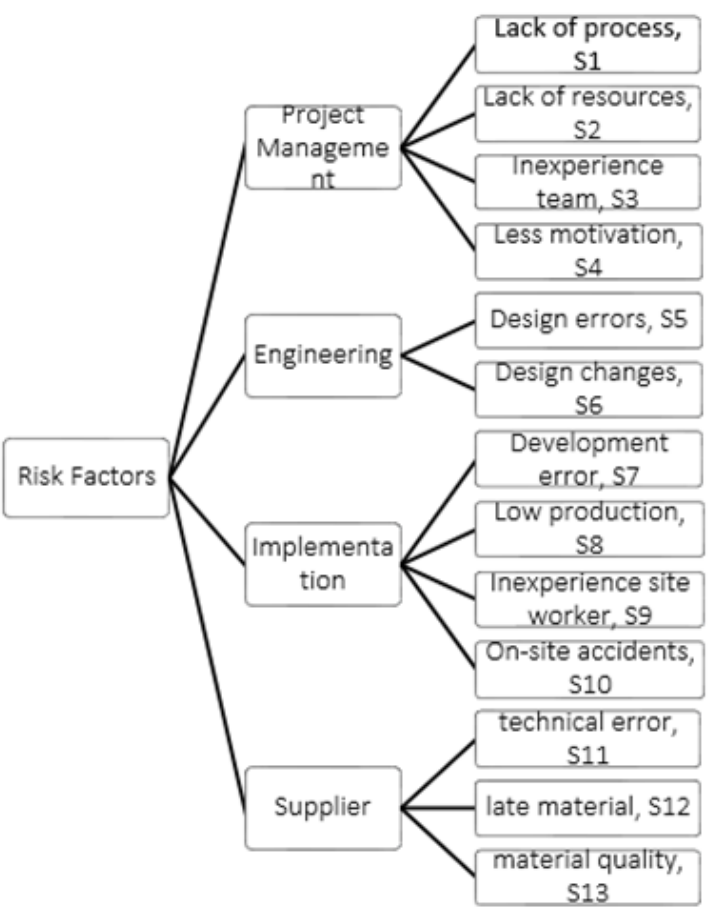

Figure 2. Objective hierarchies for the evaluation of construction risk factors

The study experts compare the significance of the risk point to another in a pair-wise manner. A factor-by-factor analysis can be achieved using questionnaires in the context of linguistic variables for a case at $n$ - level. A linguistic variable is an artificial or natural language word or phrase (Taylan et al., 2014). TFNs used in this paper reflect arbitrary evaluations of pair-wise comparisons by the experts (decision maker) which describe linguistics variables namely, "much more", "more", "same", "less", and "much less". Nieto-Morote \& Ruz-Vila (2011) proposed the triangular fuzzy conversion scales and linguistic scales, to convert such linguistic values into fuzzy scales, as depicted in Table 1.

Table 1. Triangular fuzzy scales

\begin{tabular}{|c|c|c|c|}
\hline No. & TFN values & Description & Interpretation \\
\hline 1 & $(0,0,0.3)$ & Much more & $\begin{array}{c}\text { Much more impact on overall framework of } \\
\text { project }\end{array}$ \\
\hline 2 & $(0,0.25,0.5)$ & More & $\begin{array}{c}\text { More impact on overall framework of } \\
\text { project }\end{array}$ \\
\hline 3 & $(0.3,0.5,0.7)$ & Same & $\begin{array}{c}\text { Same impact on overall framework of } \\
\text { project }\end{array}$ \\
\hline 4 & $(0.5,0.75,1)$ & Less & Less impact on overall framework of project \\
\hline 5 & $(0.7,1,1)$ & Much less & Much less impact on overall framework \\
\hline
\end{tabular}




\subsection{Numerical example to rank risk}

Fuzzy numbers are used to approximate the decision-makers' subjective assessment in assessing risk criteria. Pair-wise comparison is used in the decision-making process to form a reciprocal matrix, thus transforming qualitative data to crisp ratios and making the process simple and easy to handle. The calculations illustrated below correspond to the linguistic measurements of risk factors under the project management group.

Based on the objective hierarchies for the evaluation of construction risk, the judgment matrix of the four main categories of risk factors in construction risk is shown in Table 2-5. The triangular fuzzy numbers displayed in the matrix as a result of the aggregation of four experts' risk preferences. Taking risk factor under project management (Table 2) as an example, the expert has given a preference of the risk factor of "lack of resources" (S2) which has more impact than risk factor of "less motivation" (S4), and the result of the comparison is displayed by the fuzzy number.

Table 2. Pair-wise comparison matrix with respect to project management risk

\begin{tabular}{|c|c|c|c|c|c|}
\hline Item & S1 & S2 & S3 & S4 & Local weights \\
\hline S1 & $(1,1,1)$ & $(0.075,0.25,0.5)$ & $(0,0.25,0.5)$ & $(0.075,0.3125,0.55)$ & 0.0181 \\
\hline S2 & $(0.275,0.5,0.725)$ & $(1,1,1)$ & $(0.2,0.4375,0.675)$ & $(0.2,0.4375,0.675)$ & 0.4198 \\
\hline S3 & $(0.15,0.3125,0.55)$ & $(0.2,0.4375,0.675)$ & $(1,1,1)$ & $(0.15,0.375,0.6)$ & 0.0145 \\
\hline S4 & $(0.5,0.75,1)$ & $(0.5,0.75,0.925)$ & $(0.4,0.625,0.85)$ & $(1,1,1)$ & 0.5476 \\
\hline
\end{tabular}

Table 3. Pair-wise comparison matrix with respect to engineering risk

\begin{tabular}{|c|c|c|c|}
\hline Item & S5 & S6 & Local weights \\
\hline S5 & $(1,1,1)$ & $(0.125,0.3125,0.575)$ & 0.5186 \\
\hline S6 & $(0.075,0.25,0.5)$ & $(1,1,1)$ & 0.4814 \\
\hline
\end{tabular}

Table 4. Pair-wise comparison matrix with respect to implementation risk

\begin{tabular}{|c|c|c|c|c|c|}
\hline Item & S7 & S8 & S9 & S10 & Local weights \\
\hline S7 & $(1,1,1)$ & $(0.075,0.25,0.5)$ & $(0,0.125,0.4)$ & $(0,0.25,0.5)$ & 0.0206 \\
\hline S8 & $(0.075,0.3125,0.55)$ & $(1,1,1)$ & $(0.075,0.3125,0.55)$ & $(0.225,0.4375,0.65)$ & 0.3889 \\
\hline S9 & $(0.075,0.3125,0.55)$ & $(0,0.25,0.5)$ & $(1,1,1)$ & $(0.15,0.375,0.6)$ & 0.0083 \\
\hline S10 & $(0.45,0.6875,0.925)$ & $(0.5,0.75,0.925)$ & $(0.5,0.75,1)$ & $(1,1,1)$ & 0.5822 \\
\hline
\end{tabular}

Table 5. Pair-wise comparison matrix with respect to supplier risk

\begin{tabular}{|c|c|c|c|c|}
\hline Item & S11 & S12 & S13 & Local weights \\
\hline S11 & $(1,1,1)$ & $(0.15,0.375,0.6)$ & $(0.15,0.375,0.6)$ & 0.0435 \\
\hline S12 & $(0,0.1875,0.45)$ & $(1,1,1)$ & $(0.075,0.3125,0.55)$ & 0.0435 \\
\hline S13 & $(0.225,0.4375,0.65)$ & $(0.35,0.5625,0.775)$ & $(1,1,1)$ & 0.9130 \\
\hline
\end{tabular}


The aggregated of all four DM’s pairwise comparison.

$$
\sum_{j=1}^{4} M_{g j}^{j}
$$

$(1,1,1)+(0.075,0.25,0.5)+(0,0.25,0.5)+(0.075,0.3125,0.55)$ $=(1.15,1.8125,2.55)$

$(0.275,0.5,0.725)+(1,1,1)+(0.2,0.4375,0.675)+(0.2,0.4375$

$, 0.675)=(1.675,2.375,3.075)$

$(0.15,0.325,0.55)+(0.2,0.4375,0.675)+(1,1,1)+(0.15,0.375$

$, 0.6)=(1.5,2.125,2.825)$

$(0.5,0.75,1)+(0.5,0.75,0.925)+(0.4,0.625,0.85)+(1,1,1)$

$=(2.4,3.125,3.775)$

$$
\sum_{i=1}^{4} \sum_{j=1}^{4} M_{g j}^{j}
$$

$(1.15,1.8125,2.55)+(1.675,2.375,3.075)+(1.5,2.125$, $2.825)+(2.4,3.125,3.775)=(6.725,9.4375,12.225)$

$$
\left[\sum_{i=1}^{4} \sum_{j=1}^{4} M{ }_{g j}^{j}\right]^{-1}=\left(\frac{1}{12.225}, \frac{1}{9.4375}, \frac{1}{6.725}\right)
$$

S1 $(1.15,1.8125,2.55) \mathrm{X}(0.0818,0.106,0.1487)$

$=(0.0941,0.1921,0.3792)$

S2 $(1.675,2.375,3.075) \mathrm{X}(0.0818,0.106,0.1487)$

$=(0.137,0.2517,0.4572)$

S3 $(1.5,2.125,2.825) X(0.0818,0.106,0.1487)$

$=(0.1227,0.2252,0.4201)$

S4 $(2.4,3.125,3.775) \times(0.0818,0.106,0.1487)$

$=(0.1963,0.3311,0.5613)$

A crisp weight of the corresponding fuzzy triangular weights should be determined during the decision-making process. In order to determine the crisp weights from the fuzzy weights, Chang (2020) proposed the use of a comparison of the fuzzy numbers concept. A pair-wise comparison with the other fuzzy weights is executed using equation (3) and obtain the degree of potentially high value than these fuzzy weights. The overall score for each factor is taken among the minimum values. The minimum possible degree is calculated with these vectors as:

$$
V\left(\tilde{M}_{2} \geq \tilde{M}_{1}\right)=\sup _{y \geq x}\left[\min \left(\mu_{M_{1}}(x)-\mu_{M_{2}}(y)\right)\right]
$$

$$
\begin{aligned}
& \mathrm{V}(\mathrm{S} 1 \geq \mathrm{S} 2)=0.0596 \\
& \mathrm{~V}(\mathrm{~S} 1 \geq \mathrm{S} 3)=0.0331 \\
& \mathrm{~V}(\mathrm{~S} 1 \geq \mathrm{S} 4)=0.1391 \\
& \mathrm{~V}(\mathrm{~S} 2 \geq \mathrm{S} 1)=1 \\
& \mathrm{~V}(\mathrm{~S} 2 \geq \mathrm{S} 3)=1 \\
& \mathrm{~V}(\mathrm{~S} 2 \geq \mathrm{S} 4)=0.7665 \\
& \mathrm{~V}(\mathrm{~S} 3 \geq \mathrm{S} 1)=1 \\
& \mathrm{~V}(\mathrm{~S} 3 \geq \mathrm{S} 2)=0.0265 \\
& \mathrm{~V}(\mathrm{~S} 3 \geq \mathrm{S} 4)=0.106 \\
& \mathrm{~V}(\mathrm{~S} 4 \geq \mathrm{S} 1)=1 \\
& \mathrm{~V}(\mathrm{~S} 4 \geq \mathrm{S} 2)=1 \\
& \mathrm{~V}(\mathrm{~S} 4 \geq \mathrm{S} 3)=1
\end{aligned}
$$

Hence, the relative weight of the risk criteria is:

$$
\begin{aligned}
\mathrm{V}(\mathrm{S} 1 \geq \mathrm{S} 2, \mathrm{~S} 3, \mathrm{~S} 4) & =\min (0.0596,0.0331,0.1391) \\
& =0.0331 \\
& =\mathrm{w}^{\prime}(\mathrm{S} 1)
\end{aligned}
$$

Following the same procedure, the relative weights of other criteria are computed and shown in Table 6.

Table 6. The normalised weight values of risk factors for overall project risk

\begin{tabular}{|c|c|c|}
\hline Risks & Weights & Risk Level \\
\hline S1 & 0.02 & 11 \\
\hline S2 & 0.42 & 6 \\
\hline S3 & 0.01 & 12 \\
\hline S4 & 0.55 & 3 \\
\hline S5 & 0.52 & 4 \\
\hline S6 & 0.48 & 5 \\
\hline S7 & 0.02 & 10 \\
\hline S8 & 0.39 & 7 \\
\hline S9 & 0.01 & 13 \\
\hline S10 & 0.58 & 2 \\
\hline S11 & 0.04 & 8 \\
\hline S12 & 0.04 & 9 \\
\hline S13 & 0.91 & 1 \\
\hline
\end{tabular}


Based on the weight of criteria, the risk factor for the quality of suppliers (S13) has the highest weight, followed by the risk of accidents (S10). It can be interpreted that the potential impact on the overall risk of the project is mainly due to the quality of the suppliers. It gives a signal to project decision-makers to make effective decisions on risk action plans. Conversely, the lower impact of risk was attributed to lack of experience in the management team, development error during the engineering phase, lack of experience of the project team, technical errors, and late material supplies. This indicates that the experts in the project perceived that the risks are not significant and do not affect the overall risk of the project and hence can be ignored in the future.

\section{Conclusion and Future works}

The present study extracted four main construction risk factors namely: project management; engineering; implementation; supplier risks; and provides a framework that enables decision-makers to make effective decisions on complex issues using a fuzzy analytical hierarchy process. Figure 2 showed the importance of sub-criteria (risk factor) calculated based on the ranking of risk elements of construction risk. The final relative weight at the last level of the hierarchy will lead to a significant risk ranking. The empirical study of real project risk in the construction sector shows that fuzzy AHP is favourable for solving real-life problems which incorporated uncertainties involved in experts' judgement. In most cases, the application of fuzzy risk analysis may yield satisfactory results despite simple computation when dealing with imprecision information as compared to traditional risk assessment. Future research should consider a set of fuzzy judgments using simulation in the risk prioritisation problem.

\section{Acknowledgments}

The authors are grateful for anonymous comments and reviews on the publication of this paper.

\section{REFERENCES}

[1] Al-Shammari, M., \& Mili, M. (2019). A fuzzy analytic hierarchy process model for customers' bank selection decision in the Kingdom of Bahrain. Operational Research, (0123456789). https://doi.org/10.1007/s12351-019-00496-y

[2] Baas, S. M., \& Kwakernaak, H. (1977). Rating and Ranking of Multiple-Aspect Alternatives Using Fuzzy Sets.

[3] Chang, D. Y. (1996). Applications of the extent analysis method on fuzzy AHP. European Journal of Operational Research, 95(3), 649-655. https://doi.org/10.1016/0377-2217(95)00300-2

[4] Chen, S. (2011). A Fuzzy AHP Approach for Evaluating Customer Value of B2C Companies. 6(2), 224-231. https://doi.org/10.4304/jcp.6.2.224-231

[5] Hajjari, T., \& Numbers, F. (2014). Fuzzy Risk Analysis Based on Ranking of Fuzzy. (February), 17-29.

[6] Lee, S., \& Ph, D. (2016). Application of AHP and Fuzzy AHP to Decision-Making Problems in Construction. 52nd ASC Annual International Conference Proceedings, (2004).

[7] Ling, A., \& Xu, C. (2012). Robust portfolio selection involving options under a "marginal+joint" ellipsoidal uncertainty set. Journal of Computational and Applied Mathematics, 236(14), 3373-3393. https://doi.org/10.1016/j .cam.2012.03.023

[8] Liu, X.-W., \& Han, S.-L. (2005). Ranking Fuzzy Numbers with Preference Weighting Function Expectations. Computer and Mathematics with Application, 49, 17311753.

[9] Mousa, J. (2015). Risk Management in Construction Projects from Contractors and Owners" perspectives. Journal of Sustainable Development in Africa, 3(2), 18-24.

[10] Nieto-Morote, a., \& Ruz-Vila, F. (2011). A fuzzy approach to construction project risk assessment. International Journal of Project Management, 29(2), 220-231. https://doi.org/10.1016/j.ijproman.2010.02.002

[11] Radionovs, A., \& Užga-Rebrovs, O. (2016). Fuzzy Analytical Hierarchy Process for Ecological Risk Assessment. Information Technology and Management Science, 19(1), 16-22.https://doi.org/10.1515/itms-2016-00 05

[12] Rahnama, M. R., Kheibari, K. K., Hossein Pour, S. A., \& Najafi, M. (2012). Ranking and Investigation of Voice of Customer Index by Applying AHP Method in Local Management of Tehran Metropolis. Journal of Management and Sustainability, 3(1), 129-144. https://doi.org/10.5539/j ms.v3n1p129

[13] Reddy, G. M. (2015). Trapezoidal fuzzy numbers in extent analysis method in fuzzy AHP. 3(1965), 69-71.

[14] Saaty, T. L. (1980). The Analytic Hierarchy Process. New York: McGraw-Hill Education (Malaysia) Sdn. Bhd.

[15] Shang, K., \& Hossen, Z. (2013). Applying Fuzzy Logic to Risk Assessment and Decision-Making Sponsored by CAS / CIA / SOA Joint Risk Management Section Prepared by. Casualty Actuarial Society, Canadian Institute of Actuaries, Society of Actuaries, 1-59.

[16] Taroun, A. (2014). Towards a better modelling and assessment of construction risk: Insights from a literature review. International Journal of Project Management, 32(1), 101-115. https://doi.org/10.1016/j.ijproman.2013.03.004

[17] Taylan, O., Bafail, A. O., Abdulaal, R. M. S., \& Kabli, M. R. (2014). Construction projects selection and risk assessment by fuzzy AHP and fuzzy TOPSIS methodologies. Applied Soft Computing Journal, 17, 105-116. https://doi.org/10.10 16/j.asoc.2014.01.003 
[18] Wan Mohd, W. R., \& Abdullah, L. (2017). A New Aggregation Operator Based on Intuitionistic Fuzzy Choquet Integral. Journal of Computer Science \& Computational Mathematics, 7(4), 125-130. https://doi.org/ 10.20967/jcscm.2017.04.003

[19] Wang, Y., \& Lee, H. (2007). The revised method of ranking fuzzy numbers with an area between the centroid and original points. 55(2008), 2033-2042. https://doi.org/10.10 16/j.camwa.2007.07.015

[20] Zadeh, L. A. (1965). Fuzzy Sets * -. Information and Control, 353(8), 338-353. 